\title{
Aproximación sociohistórica comparada al Tercer Sector de Acción Social (TSAS) autonómico
}

\section{Ángel Rivero Recuenco, Ana Arriba González de Durana}

RESUMEN: En este artículo exploramos los elementos que han incidido en la configuración sociohistórica del Tercer Sector de Acción Social (TSAS) como un actor destacado en el sistema mixto de bienestar español. Teniendo en cuenta que este proceso de creación y expansión de organizaciones privadas no lucrativas que operan en el ámbito social ha sido paralelo al proceso de descentralización de buena parte de la responsabilidad sobre las políticas sociales del Estado de bienestar español a las comunidades autónomas, nos preguntamos por las diferencias que han marcado las particulares trayectorias autonómicas del TSAS.

Para ello nos basamos en fuentes secundarias y primarias (entrevistas y reuniones grupales) recogidas en el marco del proyecto PECOTSAS en una selección de casos autonómicos. Hemos estructurado el análisis comparativo a partir de tres tipos de elementos: a) los condicionantes políticos que posibilitan el TSAS; b) los condicionantes estructurales de desarrollo económico y territorial; y c) los actores sociales que protagonizan la movilización social vinculada a las organizaciones del TSAS. Los resultados apuntan a que las pautas de diferenciación autonómica del TSAS tiene raíces tanto en las formas de distribución desigual del poder resultantes del proceso de Transición democrática como en las diferencias en los patrones de desarrollo económico, distribución poblacional y tradiciones históricas de movilización social de las regiones españolas, sin perder de vista que estos elementos también inciden en diferencias intrarregionales.

PALABRAS CLAVE: Tercer Sector, Estado de Bienestar, Sistema mixto de bienestar, comunidades autónomas, Sociedad Civil, Política Social.

CLAVES ECONLIT: H53, H77, I30, L31. 
Cómo citar este artículo/How to cite this article: RIVERO, Á. \& ARRIBA, A. (2021): "Aproximación sociohistórica comparada al Tercer Sector de Acción Social (TSAS) autonómico", CIRIEC-España, Revista de Economía Pública, Social y Cooperativa, 103, 43-73. DOI: 10.7203/ CIRIEC-E.103.21514.

Correspondencia: Ángel Rivero Recuenco, Universidad de Alcalá, ángel.rivero@uah.es, ORCID: 0000-0003-4879-3946; Ana Arriba González de Durana, Universidad de Alcalá, ana.arriba@uah.es, ORCID: 0000-0003-3778-5182.

ABSTRACT: In this article, we explore the elements that have shaped the socio-historical configuration of the Third Sector of Social Action (TSSA) as a prominent actor in the Spanish welfare mix. Bearing in mind that this process of creation and expansion of private non-profit organisations operating in the social sphere has been parallel to the process of decentralisation of a large portion of the responsibility for the social policies of the Spanish welfare state to the Autonomous Communities, we examine the differences that have marked the particular trajectories of the TSSA in the Autonomous Communities.

To this end, we have relied on secondary and primary (interviews and group meetings) sources collected in a selection of regional cases in the framework of the PECOTSAS project. We have structured the comparative analysis on the basis of three types of elements: a) the political conditions that enabled the TSSA; b) the structural conditions of economic and territorial development; and c) the social actors who have played a leading role in social mobilisation linked to TSSA organisations. The results suggest that the patterns of regional differentiation of the TSSA are rooted both in the forms of distribution of power resulting from the process of democratic transition and in the differences in the patterns of economic development, population distribution and historical traditions of social mobilisation in the Spanish regions, without losing sight of the fact that these elements also have an impact on intra-regional differences.

KEYWORDS: Third Sector, welfare state, mixed welfare system, Autonomous Communities, civil society, social policy, Spain. 


\section{Expanded abstract}

\section{Comparative socio-historical approach to the Spanish regional Third Sector of Social Action (TSSA)}

Over the last four decades, the Spanish Third Sector of Social Action (TSSA) has been institutionalised as an agent of the welfare state with its own sphere of action. This process has taken place at the same time as the regional authorities have assumed responsibility for the implementation and management of social policies, particularly social services.

This article is part of the research project Comparative Perspective of the Third Sector of Social Action in the Autonomous Communities (PECOTSAS) which asks whether the need to conform to the regional welfare systems has guided the TSSA along a path of regional differentiation (in some cases, such as the Basque Country or Catalonia, in a very distinct manner, given their national peculiarity recognised in the Spanish Constitution).

More specifically, the aim of this article is to explore the elements that, over the last four decades, have influenced the socio-historical configuration of the TSSA. We examine the different factors that have marked the particular regional trajectories of the TSSA.

The article is based on the comparative study of a sample of Spanish regions following the research design of the PECOTSAS project. Within the framework of the project, primary qualitative information has been collected through in-depth interviews and focus groups, as well as secondary information (national and regional documentation and legislation).

In this article, we have relied on primary qualitative empirical material, mainly discursive, which reflects the self-awareness or historical memory of the actors in the sector themselves. The analysis has taken into account the convergence of the actors' discourses and has contrasted them with other sources (primary or secondary) in order to establish hypotheses or conjectures regarding the general meaning of the discourses analysed and the existence of plausible relationships between them and the phenomenon under investigation. In any case, we consider that the "truth" of the actors interviewed, their historical self-consciousness, is an instance (discursive, cultural, ideological) that operates on the reality of the TSSA itself, and even on its own history. This self-awareness is a representation that operates in the here and now: it defines the identity on the basis of which the actors position themselves in the face of the changes they have experienced.

We have structured the comparative analysis along three types of elements: a) the political conditions that make the TSSA possible; b) the structural conditions of economic and territorial development; and c) the social actors involved in the social mobilisation linked to TSSA organisations. 
As for the political conditioning factors underlying the current TSSA, the focus of analysis has centred on the period between the end of Franco's regime and the beginning of the democratic era. The most immediate precedents of today's TSSA date back to the civic and solidarity actors of the 19th century (ecclesiastical entities and civil associations of a solidarity nature or linked to workers' mutualism). During Franco's dictatorship, there was a conglomerate of social welfare entities, many of them of a religious nature, which carried out social action and even advocated for rights. However, the numerous social mobilisations, joined by sectors of the Catholic Church, which emerged to demand rights and collectively resolve needs not supplied by the public sector during the capitalist modernisation of the final stage of the dictatorship, especially in urban industrial areas, served as the basis for the emergence of associations that would characterise the democratic transition from 1977 onwards. These mobilisations constitute the general and immediate historical background to what, in the democratic period, was to become institutionalised in the TSSA.

In the informants' historical reconstructions, the democratic transition appears as the foundational moment of the development of the Spanish TSSA. The effects derived from the processes triggered by the end of the dictatorship and the transition to democracy delimited the conditions of possibility for the development of the TSSA in Spain. On the one hand was the recognition of a catalogue of fundamental rights and public freedoms, which enabled associations and social mobilisation to develop without the restrictions of the previous period. On the other hand, during the transition, the political and legal foundations were laid for the construction of a modern, decentralised welfare state, with its own mechanisms of government. The construction of the Spanish welfare state, supported by the corresponding regional government mechanisms, laid the foundations for the establishment of collaborative relations between the public sector and the associative sector, within the framework of a mixed system for the management of matters considered to be of a social nature. Adjustment to this framework gave way to a process of rationalisation and professionalisation of the TSSA entities, which over time have lost some of their critical vigour. This process was paralleled by the assumption of a dominant role as service-providing organisations, marked by dependence on the purposes and modes of financing established by the public administrations.

The structural conditions of economic and territorial development are represented, in the discourses collected in the research, as the origin of the needs and forms of interaction that explain the different forms of social action and development of organised civil society. In the informants' representations, the reference model of a vigorous associative movement appears to be associated with industrial economic dynamism and the related urbanisation process.

Thus, in the regions of early industrialisation, such as Madrid, Catalonia and the Basque Country, the needs (problems of industrial agglomeration, uprooting, environmental deterioration, industrial reconversion and unemployment) fuelled demands and mobilisation along with the formation of organisations supported by a thriving voluntary sector. For their part, in areas with delayed industrialisation, dispersed population settlements and territorial heterogeneity, such as Andalusia, Castile-Leon and, to a certain extent, the Valencian Community, a heterogeneous configuration can be distinguished in which the rural space has been marked 
by traditional modes of mutual assistance as opposed to the cities where the patterns have been similar to those of the industrial regions but marked by the development and decisions of the public administration. This distinction between rural and urban environments also serves to differentiate dynamics in the territories of early industrialisation.

The informants' representations converge on the leading role of the Catholic Church and of the families or those concerned in the social mobilisation that gave rise to the Spanish TSSA. References are also made to the public administration, the foundations of savings banks and financial institutions, the workers' movement and social intervention professionals, but they do not attain the relevance of these two actors.

The role of the Church appears to be based both on its traditional authority and political legitimacy during the dictatorship, and on the renewal of its social and political role that a sector of the Church undertook during this period. Church organisations opened up to social demands, promoted initiatives, and provided space and capacity for dialogue to associations that subsequently became independent. Representations are different in Catalonia, the Basque Country, Madrid and Valencia, where the Church plays an important role in the generation of the associative movement, to those of Andalusia and Castile-Leon, where its presence is more associated with traditional forms of association and charity.

In the discourses, the mobilisation of those concerned and of the 'families' seeking solutions to their problems, represent the social initiative with secular roots. In the first decades, the organisations of those concerned were oriented towards the demand for rights and the organisation of collective responses, with parents playing an active role. Subsequently, they would have redirected their action towards the provision of professionalised services and dependence on the action of public administrations. There are also differences between the regional cases: if in Catalonia, the leading role has been played by a well-established associative movement (neighbourhood, workers', leisure or Catalanist), it has been the association of families with cooperativism in the Basque Country, the neighbourhood movement in Madrid and the family initiative in Valencia.

The results indicate that, from a socio-historical perspective, the regional differences in the TSSA are rooted both in the forms of unequal distribution of power resulting from the process of democratic transition and in the differences in the patterns of economic development, population distribution and historical traditions of social mobilisation of the Spanish regions, without losing sight of the fact that these elements also have an impact on intra-regional differences. 


\section{Introducción}

La literatura especializada es prácticamente unánime en considerar que en las últimas cuatro décadas el Tercer Sector de Acción Social español (en adelante TSAS) ha crecido y se ha institucionalizado como un agente del Estado de bienestar y ha establecido un espacio de actuación propio. Este proceso ha sido paralelo a la descentralización hacia las comunidades autónomas de buena parte de la responsabilidad sobre las políticas sociales, en particular los servicios sociales. La configuración asimétrica del Estado de las Autonomías habría tenido, por tanto, su reflejo correlativo en la configuración territorialmente diferencial del TSAS. La necesidad de acomodarse a los sistemas autonómicos de bienestar, cuyas competencias y capacidades en política social se han ido consolidando en los últimos cuarenta años, habrían orientado al TSAS por la senda de la diferenciación regional.

La cuestión sobre si, en las últimas décadas, el TSAS español ha derivado en modelos diferenciados (territoriales o autonómicos), dotados de especificidades e identidad propia es el punto de partida de este trabajo, y del proyecto de investigación Perspectiva comparada del Tercer Sector de Acción Social en las Comunidades Autónomas (PECOTSAS) ${ }^{1}$ del que forma parte. Este proyecto se ha centrado en el TSAS como el ámbito de acción formado por entidades privadas de carácter voluntario y sin ánimo de lucro que, surgidas de la libre iniciativa ciudadana, funcionan de forma autónoma y solidaria en el ámbito de la acción social (POAS, 2012). Se incluyen, por lo tanto, asociaciones y fundaciones de acción social ${ }^{2}$, pero se excluyen aquellas entidades de economía social que, aunque funcionan con lógicas diferentes a las del intercambio mercantil, no descartan la actividad lucrativa ${ }^{3}$.

Desde estos puntos de partida, el objetivo del presente trabajo es identificar y analizar los factores sociohistóricos (condicionantes políticos, patrones de desarrollo económico y de asentamiento poblacional, estructuras territoriales, movilizaciones sociales...) de incidencia en la configuración del TSAS en España. Siguiendo el enfoque y los objetivos del proyecto PECOTSAS, el trabajo asume una perspectiva comparada. En este sentido, hemos considerado las diferencias territoriales derivadas de la diversidad regional española y su configuración político-administrativa como Estado de las autonomías, de modo a establecer patrones históricos comunes y particularidades regionales, o incluso locales.

1. El Proyecto PECOTSAS (Perspectiva Comparada del Tercer Sector de Acción Social) ha sido financiado en la Convocatoria 2017 de Proyectos de I+D+i de excelencia del Ministerio de Economía, Industria y Competitividad (RFA: CSO2017-85486-P). Ha sido ejecutado entre 2018 y 2021 por un equipo de investigadores e investigadoras de las Universidades de Alcalá, Universidad Jaume I de Castellón y Universidad Pablo de Olavide de Sevilla.

2. Junto con sus federaciones y confederaciones (entidades de segundo y tercer nivel) además de las entidades singulares (Cruz Roja, Cáritas y la ONCE), ONG de desarrollo y entidades religiosas que desarrollan acción social en España.

3. Entre ellas: cooperativas, mutualidades, sociedades laborales, empresas de inserción o centros especiales de empleo. A lo largo del artículo se hará referencia a movimientos o entidades de economía social, especialmente los relacionados con el cooperativismo, como factores que acompañan el proceso de las entidades del TSAS, no como parte de él. 
Hemos circunscrito el horizonte temporal del trabajo al periodo que se extiende desde el llamado segundo franquismo (Townson, 2009) hasta los inicios de la etapa democrática (grosso modo, desde principios de la década de 1960 hasta los comienzos de la década de 1980). La Transición a la democracia constituye, en buena medida, el núcleo o eje histórico principal del análisis. Las razones de esta delimitación del alcance del trabajo radican en la relevancia que, a tenor de las fuentes analizadas, tiene el citado periodo en la configuración del TSAS en el caso español, sin perjuicio de que procesos y acontecimientos posteriores hayan, sin duda, inducido efectos sobre la morfología, la estructura y las funciones del sector.

\section{Enfoque metodológico}

El trabajo se ha basado en el análisis de entrevistas abiertas con informantes clave pertenecientes al TSAS o expertos en el mismo (generalmente con un pasado vinculado al sector), así como con representantes de las Administraciones autonómicas. De modo complementario, se han considerado las aportaciones de grupos focales (formados con voluntarios y personal del TSAS) y fuentes secundarias (de carácter historiográfico o de diagnóstico del sector). Estas han sido las fuentes principales sobre las que se basa, en general, la metodología del proyecto PECOTSAS.

Partiendo de la opción metodológica asumida en la investigación, la aproximación a los factores sociohistóricos de incidencia en la configuración del TSAS se ha hecho, necesariamente, a partir del discurso de los informantes clave que constituyen la fuente principal del proyecto. Es, por tanto, una aproximación a la historia a partir del relato de dichos informantes; una aproximación cualitativa y discursiva apoyada, asimismo, en el examen de fuentes secundarias, que han permitido, en ciertos puntos, contrastar, fundamentar o complementar los discursos recogidos y analizados.

El objeto de la investigación es, en sentido estricto, fáctico (acontecimientos y procesos sociohistóricos) y no discursivo. Su objeto, en definitiva, no son las representaciones discursivas de los hechos, sino los hechos referidos en esas representaciones. Dado que el trabajo se ha elaborado, fundamentalmente, a partir del discurso de los propios actores del sector, surge la cuestión del estatuto epistemológico que podemos dar a esta autoconciencia discursiva o memoria histórica de los actores (su "valor de verdad", podríamos decir). Ciertamente el propósito de este trabajo no ha sido realizar un análisis crítico o ideológico de la memoria histórica de los informantes entrevistados. Sin duda, nuestra aproximación al nivel fáctico de la realidad está mediada por la posición social e institucional de los entrevistados, pero el análisis de estas posiciones discursivas, de sus efectos sobre el sentido y de la intencionalidad latente de los discursos, de las configuraciones narrativas a que dan lugar, etc., sería, en rigor, el objeto de otro trabajo y de otra investigación (de sumo interés, por otra parte).

De cualquier modo, la entrevista abierta, a diferencia del grupo de discusión, es una técnica que alcanza pleno rendimiento en la reconstrucción de acciones pasadas; una técnica pertinente, por tanto, para el esclarecimiento de hechos y procesos de naturaleza histórica o biográfica (Alonso, 1995). Por otro lado, en las prácticas de la investigación social cualitativa, es 
un lugar común considerar que la convergencia de los discursos de los informantes constituye un primer criterio de validación de la adecuación de las representaciones discursivas con respecto a los hechos que constituyen su referente. Sumada al contraste con otras fuentes (primarias o secundarias), estas convergencias permiten establecer hipótesis o conjeturas acerca de la existencia de relaciones plausibles entre los discursos y el fenómeno objeto de investigación. Este es el criterio que hemos seguido para seleccionar, del conjunto de los discursos recogidos, lo pertinente y lo relevante a efectos de identificar factores sociohistóricos de incidencia en la configuración del TSAS.

\section{Diseño de investigación y trabajo de campo}

La estrategia de investigación del proyecto PECOTSAS se ha basado en una muestra de siete casos autonómicos: Andalucía, Cataluña, Castilla y León, Comunidad Valenciana, Madrid, Murcia y País Vasco. Estas comunidades autónomas se seleccionaron siguiendo criterios de heterogeneidad en desarrollo económico, tamaño poblacional, así como estructura territorial y administrativa. En estas comunidades se ha realizado 48 entrevistas en profundidad y 14 grupos focales.

Las entrevistas semiestructuradas se realizaron a informantes y expertos seleccionados entre investigadores, profesionales de los servicios sociales públicos e integrantes del TSAS. Se llevaron a cabo entre los meses de abril y septiembre de 2019, basadas en un guion semiestructurado en torno a los aspectos del TSAS objeto del proyecto de investigación: la regulación jurídica y normativa, modelos de financiación e institucionalización, factores históricos y dinámicas de colaboración interna y externa (administraciones públicas, movimientos sociales, actores sociales, empresas de prestación de servicios o economía social).

Por cada comunidad autónoma se realizaron dos grupos focales: uno con mandos intermedios y otro con voluntariado. Se realizaron entre los meses de abril y mayo de 2021 en condiciones de limitación de movilidad y distancia física debido a la pandemia COVID-19. Por ello, se realizaron online (empleando la aplicación Zoom). Se empleó un guion abierto a partir de las mismas cuestiones que se habían tratado en las entrevistas al que se añadieron otras de valoración del impacto de la pandemia. A partir de las entrevistas y los grupos focales se elaboraron siete informes autonómicos que constituyen el material de base para el análisis de los aspectos objeto de análisis del proyecto ${ }^{4}$.

4. Para la identificación de las fuentes de las que proceden los verbatims (reproducciones literales) empleados en el artículo, se especificarán los siguientes rasgos:

- Tipo de fuente: Entrevista; Grupo Focal.

- Tipo de informante: Internos al sector; Externos y grupos de interés; Mandos Intermedios; Voluntariado.

- Comunidad Autónoma: Andalucía, Cataluña, Castilla y León, Comunidad Valenciana, Madrid, Murcia y País Vasco. 


\section{Estructura del trabajo}

Tras una descripción general e introductoria de la evolución histórica del TSAS, el trabajo se estructura a partir de los factores de incidencia en la determinación de las identidades y las morfologías del sector. Los hemos agrupado bajo tres categorías: a) condicionantes políticos, b) condiciones estructurales (desarrollo económico y asentamiento poblacional) y c) actores sociales clave en el desarrollo histórico del sector. Por último, las conclusiones sintetizan los resultados del trabajo y plantean posibles líneas de discusión e investigación.

\section{Marco histórico general: Cuatro décadas de crecimiento e institucionalización del TSAS español}

Las raíces históricas e institucionales de la actuación cívica solidaria son profundas y es posible trazar sus trayectorias desde finales de la Edad Media (Casado, 2008). Los antecedentes más inmediatos del hoy llamado TSAS se remontan a actores cívicos y solidarios del siglo XIX a través de la actuación de entidades eclesiásticas y asociaciones civiles o vinculadas al asociacionismo o mutualismo obrero (Marbán y Rodríguez Cabrero, 2006; Rodríguez Cabrero y Sosvilla, 2018; Rodríguez Cabrero, 2020).

Durante la Dictadura franquista, existía ciertamente un conglomerado de entidades sociales, que podrían calificarse grosso modo de asistenciales, muchas de ellas de carácter religioso, que desarrollaban labores de acción social e incluso de abogacía de derechos. Sin embargo, estas funciones se vieron restringidas por la falta de libertades y limitadas por el bajo nivel de desarrollo de la sociedad civil.

En la etapa final de la Dictadura, la modernización capitalista de España, derivada en buena medida del cambio en la política económica que acontece con el Plan de estabilización de 1959 y los sucesivos Planes de desarrollo de la década posterior, da lugar a la generalización de patrones de consumo masivo y al crecimiento de las clases trabajadoras y medias (Marbán y Rodríguez Cabrero, 2006). En este contexto, especialmente en las zonas urbanas con mayor presencia de actividad industrial, emergen numerosas movilizaciones sociales, orientadas a reclamar derechos y a resolver colectivamente necesidades no suplidas por el sector público. También ciertos sectores de la Iglesia Católica participarán de estos procesos, bien atestiguados historiográficamente (Townson, 2009; Romeo et al, 2012; Juliá, 2017; Gil Pecharromán, 2018). La Ley de Asociaciones de 1964 y el impulso a las asociaciones familiares del Movimiento Nacional van a favorecer la proliferación de iniciativas vecinales (especialmente activas en Madrid y Barcelona) y de "cabezas de familia" que, aun compartiendo espacios funcionales e intereses distintos, van a converger y a servir de base a la eclosión asociativa que caracterizará a la Transición democrática a partir de 1977 (Radcliff, 2009). 
Sobre la base de estas movilizaciones emergentes, a lo largo de la etapa final de la dictadura, casi sin solución de continuidad (aunque políticamente es indudable que sí hubo ruptura, al menos una "ruptura pactada"), va a desplegar sus efectos el proceso de transformación política que conocemos como Transición. Las movilizaciones de los años 1960 del pasado siglo constituyen los antecedentes históricos generales e inmediatos de lo que, ya en el periodo democrático, va a institucionalizarse en la forma de TSAS.

A pesar de que no abundan trabajos monográficos sobre el desarrollo histórico reciente del TSAS, se han propuesto periodizaciones que, aun siendo relativamente heterogéneas, muestran hitos y trayectorias similares sobre la evolución del sector desde la Transición (Alberich, 2007; Marbán, 2014; Marbán y Rodríguez Cabrero, 2006; Mora, 2020; Rodríguez Cabrero y Marbán, 2015; Romeo et al, 2012).

La etapa de 1977 a 1994 se caracteriza por la reconstrucción de la sociedad civil y el desarrollo de un marco para la expansión e institucionalización de las políticas sociales que permite al TSAS crecer tanto cuantitativa como cualitativamente. El proceso de transferencia a las CCAA de responsabilidades de política social, especialmente de los servicios sociales, crea un espacio para el crecimiento de TSAS a nivel regional y municipal. El TSAS refuerza su papel en la prestación de servicios sociales y comienza su profesionalización a la que vez que va disminuyendo su papel como espacio de participación y reivindicación (Alberich, 2007).

A mediados de los años noventa comienza una nueva etapa de crecimiento organizativo y consolidación institucional para el TSAS, basada en su papel en la prestación de servicios y gestión de problemas sociales. Se desarrolla un sistema mixto del bienestar (welfare-mix) en el que el Estado se repliega bajo lógicas de descentralización administrativa, subsidiariedad y responsabilidad social e individual, y en el que el sector no lucrativo crece sin la presencia del sector privado lucrativo. Este crecimiento no es equilibrado, dado que el TSAS presenta rasgos de atomización, de dualidad entre entidades grandes o muy pequeñas, carece de alianzas, muestra fuerte dependencia financiera, sus funciones cívicas decaen, se reduce su base social y entra en competencia con el sector lucrativo (Rodríguez Cabrero y Marbán, 2015).

El impacto de la Gran Recesión de 2008 marca el inicio de una tercera etapa en la que el TSAS se enfrenta a varias crisis simultáneas: se incrementan las personas en situación de pobreza, colapsan sus fuentes de financiación tanto por los recortes de los presupuestos públicos, como por la práctica desaparición de fuentes privadas, principalmente las obras sociales de las Cajas de Ahorro, al tiempo que trata de mantener equipos humanos y estructuras y hacer frente al incremento de barreras administrativas (Mora, 2020). La crisis incrementó las tensiones entre las funciones del TSAS (reivindicación, representación de intereses y gestión prestacional), mostrando el anquilosamiento de la función cívica y las inercias organizativas que habían acompañado su crecimiento. Este periodo, sin embargo, finaliza con varios avances, como son la constitución de la Plataforma del Tercer Sector en 2012, la creación de la Comisión de Diálogo Civil en 2013 y la Ley 43/2015 del Tercer Sector de Acción Social en octubre de 2015.

Este es, a grandes rasgos, el marco en el que se inscribe la evolución histórica del TSAS en España. Centrando el análisis, de acuerdo con la delimitación del alcance temporal de este trabajo, en las primeras etapas de esta evolución, exponemos a continuación los principales factores sociohistóricos que han incidido en la configuración del sector. 


\section{Factores sociohistóricos de incidencia en la configuración del TSAS}

\subsection{Condiciones políticas que posibilitan el desarrollo del TSAS: Transición a la democracia y Estado de bienestar}

En la memoria de los informantes entrevistados, así como en las reconstrucciones históricas disponibles en las fuentes consultadas, la Transición a la democracia aparece como una suerte de "momento fundacional" en el desarrollo del TSAS en todo el territorio del Estado. En este sentido, constituye un factor decisivo común a todas las regiones españolas. La ruptura con el periodo anterior, y la apertura consiguiente de posibilidades que implica la Transición ("La ilusión inicial en un momento, como el de la Transición, en el que 'muchas cosas' estaban por hacer", Romeo et al, 2012: 21), van a incidir sobre contextos económicos, territoriales y demográficos diferentes, de modo que sus efectos finales sobre la configuración del TSAS no van a ser homogéneos en las distintas regiones españolas.

La Transición a la democracia implica tres efectos fundamentales para la constitución del TSAS:

1. Da lugar al fin de las restricciones formales al reconocimiento de derechos civiles, políticos y sociales; un reconocimiento que establece el marco legal que va a permitir la constitución del TSAS como un actor organizado y el pleno ejercicio de sus funciones.

2. En línea con lo anterior, debido a la apertura de posibilidades inherente a la ruptura con el periodo previo, la Transición supone un impulso fundamental para el desarrollo de la sociedad civil organizada. En este momento tiene lugar una auténtica eclosión de iniciativas y movimientos sociales de signo diverso (además de la renovación de otros, ya existentes); movimientos que con el tiempo se irán "modernizando" siguiendo dinámicas de profesionalización, racionalización y gerencialización, intensificando la especialización del sector por campos de acción y por tipos organizativos.

3. La Transición abre el camino a un desarrollo sin precedentes de las políticas sociales y sus dispositivos de gobierno, que van a constituir el espacio de interacción en el que las Entidades del Tercer Sector de Acción Social (en adelante ETSAS) van a desplegar sus acciones y en el que van a encontrar finalmente su lugar estratégico y operativo. En un contexto global de reestructuración y contención, la expansión del Estado de bienestar español y la institucionalización del TSAS mediante la colaboración con los poderes públicos forman parte del mismo proceso (Marbán y Rodríguez-Cabrero, 2006). 
Este último efecto es, sin duda, decisivo. De hecho, en los discursos recogidos tiende a reconocerse, de forma más o menos explícita , como el factor crítico que explica y define el desarrollo del TSAS: la modernización de las Administraciones públicas, la constitución del Estado autonómico y el desarrollo del Estado del bienestar (sistema mixto de bienestar y prevalencia de la provisión de servicios) se enuncian como factores dinamizadores clave en los procesos de configuración, modernización y profesionalización del sector en las últimas décadas.

Lo cierto, aunque este tema excede el propio significado de la Transición como acontecimiento, es que el desarrollo del dispositivo de gobierno de la política social ha ido dando lugar al establecimiento de las "reglas de juego" que han condicionado la actuación de las ETSAS (por la vía del desarrollo normativo y del establecimiento de planes de actuación y mecanismos de financiación en las distintas comunidades autónomas). De este modo, se ha ido definiendo el estatus y el rol de las ETSAS, en el marco de unos sistemas de bienestar reconstituidos como modelos mixtos. En este marco, la interacción entre las entidades y las Administraciones públicas irá tomando la forma de una dialéctica de difícil resolución: el dilema entre la acomodación funcional de las ETSAS a los dispositivos de gobierno autonómicos, por un lado, y la preservación de sus señas de identidad originarias, por otro, se inscribe en estas dinámicas.

\subsection{Condiciones estructurales: desarrollo económico y estructuración territorial}

Bajo este rubro, englobamos un conjunto de aspectos que remiten al patrón de desarrollo económico, a la estructura territorial y a los modos de asentamiento característicos de las regiones que constituyen la muestra estudiada en esta investigación. Se trata, en definitiva, de aspectos de carácter contextual y estructural que dan razón de la diversidad económica, geográfica y demográfica de los territorios en los que las ETSAS se han constituido y han desplegado sus acciones, influyendo, como veremos, en su morfología y su dinámica.

\section{El patrón de desarrollo y sus efectos}

Partimos de un lugar común: los procesos de desarrollo económico e industrialización han inducido efectos diferenciales sobre la movilización y asentamiento poblacional en el conjunto de España y en el interior de sus regiones. Estas dinámicas diferenciales han dado lugar históricamente a estructuras de necesidades también diferentes, derivadas de las migraciones internas y la concentración poblacional en las ciudades, así como de las externalidades generadas por las aglomeraciones industriales. Todo ello ha influido en las motivaciones de la acción social y en el desarrollo de la sociedad civil organizada. En definitiva, el grado de industrialización/urbanización ha condicionado históricamente la configuración de los tejidos asociativos territoriales, originariamente más o menos dinámicos y reivindicativos, y más o menos orientados a la cooperación o al conflicto con los poderes políticos y económicos. Tal es la representación que emerge en los discursos recogidos. 
Sobre la base de las entidades territoriales delimitadas como muestra en esta investigación, podemos establecer una primera distinción entre:

- Regiones de industrialización históricamente temprana (dentro del retraso general con que estos procesos han acontecido en España).

- Regiones en las que la industrialización ha acontecido con retraso, y de modo parcial o selectivo.

Esta distinción constituye una primera ordenación, más o menos gruesa, de los territorios estudiados. A esta clasificación preliminar iremos añadiendo consideraciones relativas a la estructura interna de las regiones estudiadas e incluso algunos casos de áreas locales que presentan particularidades significativas.

\section{Regiones de industrialización temprana y patrón de desarrollo concentrado}

A efectos del propósito analítico de nuestra investigación, estas regiones se caracterizan por una marcada polarización territorial en torno a grandes ciudades y coronas metropolitanas, en las que destaca la implantación relativamente temprana de grandes empresas y la elevada concentración de proletariado industrial procedente de migraciones internas. Se trata de territorios en los que ha dominado históricamente un patrón de desarrollo concentrado, basado en la implantación de la gran empresa y el gran capital en áreas industriales urbanas.

En la muestra territorial estudiada, en esta categoría estarían Madrid y sus coronas metropolitanas (especialmente la corona sureste), Cataluña (Barcelona y su área industrial) y el País Vasco (Vizcaya, en especial Bilbao y Margen izquierda del Nervión). Los casos de Madrid y, en Cataluña, Barcelona son expresivos, además, del importante efecto de capitalidad provocado por estas ciudades, que se extiende al conjunto del territorio nacional, en el caso de Madrid, y sobre la Comunidad Autónoma, en el caso de Barcelona.

En estas zonas, este modo de industrialización ligado históricamente a la gran empresa y al gran capital ha generado contextos demográficos y sociales especiales, unas problemáticas específicamente acentuadas que han favorecido el surgimiento de movimientos sociales reivindicativos, orientados a resolver los problemas derivados de la aglomeración industrial, la concentración desordenada de la población en el medio urbano, el desarraigo social, el deterioro ambiental y, en ciclos sucesivos, el alto nivel de desempleo provocado por la crisis de las grandes empresas. El desarrollo histórico de una cultura de reivindicación y movilización obrera ha influido, sin duda, junto a otros factores, en la formación temprana de un rico tejido de entidades (movimientos vecinales y cooperativos, asociaciones de mujeres o de familias afectadas por situaciones de discapacidad, etc., apoyados con frecuencia por organizaciones de raíz religiosa o entreverados con estas), así como en la persistencia de una tradición asociativa y de voluntariado que, pese a los cambios, continúa en nuestros días.

Se van creando una serie de circunstancias que a mi juicio hacen... desarrollan el movimiento asociativo, un movimiento asociativo en buena parte de defensa, pero en otra parte de 
solidaridad, o sea, de decir: 'oye, vamos a hacer la cooperativa' (...). Eran cooperativas que organizaban los propios trabajadores para sobrevivir (...). Hay una tradición en Vizcaya de que hace que sea una sensibilidad... a mi juicio, una sensibilidad más fina con los problemas (...). Y una iniciativa mayor.

(Entrevista 21, Internos al sector, País Vasco)

En las entrevistas realizadas, el encadenamiento causal entre necesidad y movilización sería el factor explicativo de la mayor consistencia del tejido asociativo en estas zonas (este encadenamiento es señalado reiteradamente en los discursos recogidos, muy enfáticamente, por ejemplo, en el caso de Vizcaya). Un tejido formado por entidades en las que destaca un posicionamiento de marcada vocación reivindicativa frente a los poderes públicos y económicos, en un contexto caracterizado por la gran empresa industrial y sus externalidades. En este sentido, el impacto de las crisis y las reconversiones industriales ha sido especialmente notable "porque se desmantela el tejido industrial (...) y eso hace que se respire más el Tercer Sector (...) como consecuencia de la emergencia de más necesidades" (Entrevista 20, Internos al sector, País Vasco).

Con todo, estas apreciaciones generales deben matizarse, porque las variables patrón de desarrollo/patrón de asentamiento que hemos utilizado para efectuar una primera delimitación a nivel regional operan, asimismo, en el interior de las regiones.

En el caso de Madrid, por ejemplo, se identifican tres áreas diferenciadas, correlativas a tres espacios diferenciales de desarrollo socioeconómico: el área de la capital, el de las grandes ciudades del sureste y el Madrid rural, con una parte cuasidesértica, la llamada Sierra Pobre. Tres espacios que dan lugar a configuraciones específicas de entidades sociales, que, tentativamente, podrían calificarse como globales (ligadas al fuerte efecto de capitalidad que induce la ciudad de Madrid; efecto que opera a nivel nacional, no solo regional), regionales/identitarias (vinculadas, básicamente, a los movimientos sociales de las ciudades del sureste y también de los barrios de la capital) y tradicionales o comunitarias (en el medio rural, con pautas similares a las que se dan en este medio en otras regiones). En el decir de los informantes entrevistados, "Madrid es una potencia de entidades sociales" (Entrevista 12, Externos y grupos de interés, Madrid), ciertamente; pero, al mismo tiempo, "es muy especial" (E11, Externos y grupos de interés, Madrid)), "es una mezcla" (E14, Internos al sector, Madrid).

También en Cataluña el TSAS es heterogéneo, en paralelo a la heterogeneidad interna de la Comunidad Autónoma. Al igual que en Madrid, aunque haya diferencias, el efecto de capitalidad provoca desequilibrios en la consistencia y articulación regional del sector. En Cataluña se da una concentración muy elevada de entidades en la ciudad de Barcelona, donde se ha generado un tejido de asociaciones con más musculatura y mayor capacidad para articularse (las sedes centrales de las ETSAS se ubican en la Ciudad Condal, lo que genera todo un ecosistema de entidades en torno a Barcelona). Además, la concentración de población en Barcelona y su área de influencia hace que las entidades se concentren asimismo en este espacio, desplegando "efectos de llamada" que realimentan los desequilibrios regionales: "es mucho más fácil ser discapacitado en Barcelona que en un pueblo de Lérida" (Entrevista 26, Externos y grupos de interés, Cataluña). 
El caso del País Vasco presenta también particularidades internas. La articulación del territorio de Euskadi en el eje rural/urbano no parece un factor que contribuya significativamente por sí mismo a explicar la configuración e identidad del TSAS. El carácter urbano y rural del territorio se desdibuja con frecuencia, y además su conectividad es muy elevada, como también la densidad de los servicios en poblaciones rurales: "Bilbao es una ciudad, y a diez minutos tienes un pueblo que se puede considerar como rural, pero con una serie de servicios que pueden ser perfectamente (...) los de una ciudad" (Entrevista18, Externos y grupos de interés, País Vasco).

Los factores territoriales de incidencia directa en la estructuración del TSAS tendrían más que ver con patrones de asentamiento poblacionales, históricamente ligados a las dinámicas diferenciales de desarrollo económico de la región que suscitaron, a su vez, diferentes necesidades a la población, a las que responden, finalmente, diferentes configuraciones y formas de distribución de las ETSAS en los tres territorios vascos.

Vizcaya, el territorio más poblado, concentra más del ochenta por ciento de su población en el Gran Bilbao, lo que da lugar a que, en el ámbito de la exclusión, la mayor parte de las asociaciones y los recursos se concentren en esta zona (aunque en otros ámbitos de actuación, como en discapacidad, la pauta de concentración es más equilibrada geográficamente). En todo caso, las necesidades provocadas por el patrón de desarrollo económico (industrialización concentrada) indujeron en este territorio, como hemos visto, pautas muy activas de movilización social y la formación de un tejido asociativo especialmente reivindicativo.

Guipúzcoa es un territorio más disperso y homogéneo en su distribución demográfica. La zona de Donostialdea tiene cierta similitud con la pauta del Gran Bilbao, pero su patrón de industrialización se articula a partir de redes de pequeñas empresas locales y de base familiar, en contextos territoriales estructurados por núcleos de población de pequeño o mediano tamaño, y con una distribución poblacional más equilibrada que en las áreas de industria concentrada. En estas zonas, la distinción entre rural y urbano puede llegar a desdibujarse. En País Vasco, la distinción hecha por los informantes es muy enfática respecto a la oposición de los modos de industrialización guipuzcoano y vizcaíno, y con efectos diferenciables sobre la configuración de sus respectivos TSAS. El patrón de desarrollo guipuzcoano, que podría caracterizarse como local y endógeno, se soporta sobre unas relaciones más fluidas, menos conflictivas, entre capital y trabajo:

Son pequeñas empresas familiares, que van creciendo, con una cultura un poco diferente, porque todo eso va creando culturas de participación; mientras que aquí, en lo que es la margen izquierda [del Nervión], es la gran empresa, y yo soy el empleado, y entonces se genera una especie de decir: 'voy a reivindicar, pero mi función es reivindicar y mi enemiga es la empresa'; hay otras zonas (...) donde la relación es de diferente manera (...), una relación de mayor proximidad, de mayor implicación, porque la empresa es mía también (...). Y en Guipúzcoa se aproxima a este modelo.

(Entrevista 21, Internos al sector, País Vasco)

Correlativamente, las formas de respuesta social ante los problemas vividos habrían sido menos conflictivas, más colaborativas con los agentes económicos. Es un contexto que habría 
dado lugar a la emergencia de un TSAS constituido por entidades muy orientadas a lo local, en estrecha conexión con las formas de economía social y el mundo del cooperativismo, muy presentes como motores de desarrollo en la zona. Con todo, los informantes entrevistados identifican en Guipúzcoa un menor grado de movilización social y un menor desarrollo del TSAS (tomando Vizcaya como referencia) cuyas entidades, por otro lado, han establecido relaciones más cooperativas, menos conflictivas o reivindicativas, con las Administraciones públicas.

En Álava, Vitoria-Gasteiz reúne al setenta y cinco por ciento de la población, lo que implica una alta concentración de servicios en la capital y una elevada prevalencia de la prestación pública directa. Todo ello se ha traducido en que la presencia del sector sea menor que en los otros territorios, esté localizada en la capital y sus líneas de actuación estén menos orientadas a la provisión de servicios.

Todo este panorama, más allá de las particularidades internas a las regiones, confirma, en cualquier caso, la significación general de los patrones de desarrollo económico y de asentamiento poblacional en las formas adoptadas por el sector: estas variables segmentan, en primer lugar, a las regiones, y, en un segundo nivel de análisis, a los territorios internos a las regiones. Siempre con efectos sobre la morfología y la dinámica de sus tejidos de entidades.

No obstante, y por último, en una aproximación sociohistórica y comparativa a los efectos del contexto económico, territorial y demográfico sobre el TSAS, hay que tener en cuenta que el grado de industrialización es insuficiente, por sí solo, para dar razón de las configuraciones adoptadas por las entidades del sector (a nivel regional o al interior de estas). También es relevante el modo de industrialización, que divide internamente a los territorios según un patrón de desarrollo concentrado, basado en la implantación de la gran empresa y el gran capital en áreas industriales urbanas, por un lado; y las formas de industrialización endógena, basadas en un tejido difuso de pequeñas empresas, con frecuencia de tipo familiar, muy arraigadas en el tejido social local y rural, por otro (Vázquez Barquero, 1988). El caso de Guipúzcoa, comentado supra, constituye un ejemplo de este modo de desarrollo y de sus efectos sobre la configuración del TSAS (probablemente susceptible de extenderse a otras zonas de industria endógena).

\section{El retraso en la industrialización y el peso de lo rural}

El retraso en los procesos de industrialización, y su menor incidencia comparativa, unido al peso histórico de una economía y un patrón de asentamiento rurales, caracterizan principalmente a Castilla y León, afectada en las últimas décadas por intensos procesos de migración hacia cabeceras comarcales y capitales de provincia que han provocado el vacío demográfico de extensas zonas rurales. Andalucía comparte rasgos con la vieja Castilla (retraso económico e industrialización comparativamente menor a otras zonas, importancia de lo rural y sus modos de relación tradicionales), con algunas especificidades (como el efecto histórico de la economía latifundista, notable en Andalucía). Ciertamente, también se observa una acusada dinámica de concentración poblacional en las ciudades, pero sus efectos demográficos no son 
comparables a los de Castilla y León. El caso de la Comunidad de Valencia podría asimismo encajar en esta categoría de regiones, aunque con matices particulares.

Andalucía y Castilla y León se caracterizan, además, por su extenso tamaño, lo que induce efectos muy acusados de dispersión poblacional y heterogeneidad territorial que van a influir correlativamente en la heterogeneidad de sus respectivos TSAS. También en la Comunidad Valenciana, aunque de mucho menor tamaño, se observa el efecto de un territorio heterogéneo (y desvertebrado), con una marcada delimitación entre zonas rurales y urbanas sobre la configuración del TSAS regional.

En Castilla y León, el factor crítico identificado es, ante todo, el desarrollo del dispositivo de gobierno autonómico, que emerge en las entrevistas como principal factor de incidencia en la expansión, estructuración y racionalización del sector. En este sentido, se señala que las ETSAS castellanoleonesas son todavía muy dependientes de la Administración regional.

Los informantes entrevistados sí identifican la importancia del patrón de asentamiento disperso y los desequilibrios poblacionales, así como el peso que lo rural ha tenido y continúa manteniendo en la región. Estos elementos contextuales habrían inducido una configuración dual del TSAS autonómico, a partir de la diferenciación entre el tejido asociativo presente en el medio rural (ETSAS de orientación tradicional y comunitaria que gravitan en torno a objetivos identidad local y revitalización de la cultura rural) y el concentrado en las capitales (entidades más modernas y progresivamente profesionalizadas, en línea con la pauta general de racionalización del TSAS en el conjunto del Estado). Con todo, en los discursos recogidos la distinción rural/urbano tiende a difuminarse ante el desarrollo del dispositivo de gobierno y el impulso general a la modernización/profesionalización del sector (el TSAS del ámbito rural se estaría diluyendo en el conjunto del TSAS regional).

En Andalucía, los entrevistados identifican el retraso socioeconómico de la región como punto de partida. El peso de la economía agraria y de lo rural, con los modos de relación que le son propios, han sido notables en la región. A pesar de los planes de modernización implementados durante el franquismo, y de la dinámica de concentración de la población en grandes núcleos rurales, los efectos culturales y sociales de la economía latifundista van a dejar su impronta sobre buena parte del territorio andaluz.

Estas circunstancias han inducido efectos sobre la cultura asociativa y la consiguiente formación del TSAS andaluz. La conexión del sector con los movimientos de tradición obrera, así como con el movimiento cooperativista, y en general el desarrollo la sociedad civil organizada, se han visto debilitados o retrasados con respecto a lo que acontece en otras zonas de España. En Andalucía, las formas de solidaridad organizada han estado fuertemente encauzadas a partir de modos tradicionales de asistencia mutua o por servicios asistenciales no garantistas gestionados por grandes ayuntamientos, diputaciones o cajas de ahorro.

La representación que emerge en las entrevistas es de la de un TSAS más concentrado en las ciudades que en las zonas rurales (y con más presencia en la costa que en el interior). En las ciudades andaluzas se identifican dinámicas históricas asimilables a las observadas en las zonas de industrialización temprana comentadas supra: el movimiento vecinal andaluz tuvo una importancia notable en barrios urbanos desfavorecidos a lo largo de la década de 1970 y 
hasta mediados de los años '80. En estas zonas, se van a establecer sinergias entre la Iglesia de base y el movimiento vecinal (Flores, 2012), con el fin de reivindicar derechos y articular soluciones a las necesidades sociales vividas por los vecinos.

El TSAS está, en todo caso, mucho menos presente y menos articulado en el mundo rural, donde se observa un marcado localismo en las entidades junto a la pervivencia de pautas de acción social tradicionalmente orientadas hacia la autoayuda: "los pueblos se han ido organizando para cubrir sus propias necesidades y eso sigue ocurriendo todavía" (Entrevista 5, Internos al sector, Madrid).

Por otro lado, hay que tener en cuenta el extenso tamaño de la región y la diversidad que le es propia. En las entrevistas realizadas, es recurrente la idea de que la dispersión geográfica y la diversidad de la región, unidas a su complejidad administrativa, dificultan la cohesión y la presencia homogénea de las ETSAS en el territorio andaluz. Ello va a incidir en la fragmentación y la dispersión del sector (aunque se constatan últimamente algunos cambios, en la línea de la reorganización de pequeñas asociaciones de autoayuda locales bajos fórmulas de federación).

De modo semejante al caso de Castilla y León, la percepción de los informantes andaluces es que el TSAS regional es muy dependiente de la Administración. Sus formas organizativas e incluso sus objetivos se acomodan a lo dispuesto administrativamente para acceder a las fuentes de financiación pública disponibles. En cualquier caso, resulta significativa la representación que los informantes entrevistados hacen del sector social andaluz: una representación que se elabora por contraposición a otros modelos regionales de TSAS presentes en zonas de mayor tradición industrial (Cataluña y el País Vasco, especialmente), que son percibidos como más autónomos y consolidados.

El caso de la Comunidad Valenciana podría, a grandes rasgos y con bastantes matices, incluirse en esta categoría de regiones de industrialización tardía donde la economía agraria y las formas de relacionalidad rural han tenido históricamente un peso significativo. En términos económicos, la Comunidad Valenciana ha tenido históricamente cierto nivel de actividad industrial concentrada en algunos núcleos urbanos (Valencia, Sagunto, Elche...), que contrasta con el peso de la economía agraria en las amplias zonas rurales de la región, donde se ha dado, además, una relativamente importante tradición cooperativa. En estas zonas rurales, han predominado las formas de relación basadas en la ayuda mutua y la solidaridad entre iguales propias de la economía social y de las redes familiares/comunitarias.

La Comunidad Valenciana conforma además un espacio muy heterogéneo en su estructura territorial y de asentamiento poblacional. Según los informantes entrevistados, se trata de un territorio "desvertebrado", lo que va a incidir en la propia configuración del TSAS regional. Valencia es una Comunidad Autónoma longitudinalmente extensa, de configuración espacial alargada, desconectada entre sus tres provincias, con una división muy definida entre los ámbitos rural y urbano, en la que "la concentración de las poblaciones en grandes y medianas ciudades ha dejado sin cubrir amplias zonas rurales" (Entrevista 41, Expertos y grupos de interés, Comunidad Valenciana). Esta desvertebración (intencional, incluso, según algunos) habría inducido la propia atomización histórica del TSAS, con entidades localistas, muy apegadas al territorio concreto de origen: "No se ha querido vertebrar este territorio y por lo tanto 
el propio tercer sector es desvertebrado absolutamente" (Entrevista 42, Expertos y grupos de interés, Comunidad Valenciana).

En estas condiciones, la configuración del TSAS valenciano reproduce la pauta de dualización rural/urbano que ya hemos visto en los casos de Andalucía y Castilla y León: el TSAS valenciano se ha desarrollado sobre todo en los municipios urbanos de más de veinte mil habitantes, económicamente más dinámicos, donde las entidades sociales habrían ido sustituyendo a las tradicionales redes familiares y comunitarias de apoyo. En las zonas rurales, la respuesta a las necesidades sociales ha tenido una base comunitaria e informal, y la implantación del TSAS ha sido residual, aunque últimamente con cierta significación para personas (sobre todo migrantes) sin lazos previos con las comunidades rurales:

Los que acuden a las ONG (...) o a los servicios sociales del Ayuntamiento son gente inmigrante o que no tiene familia, porque si tienes familia como que está mal visto que vayas allí (Grupo Focal 9, Voluntariado, Comunidad Valenciana).

La realidad del pueblo este no es la misma que la de la ciudad de Alicante o de Elche..., ni estamos aquí organizados con asociaciones directamente del pueblo y las necesidades pues se cubren más echando mano de la familia, (...) en un pueblo las cosa funcionan de otra manera."

(Grupo Focal 9, Voluntariado, Comunidad Valenciana)

De esta primera delimitación, sobre la base de las regiones, podríamos extraer una conclusión: en términos sociohistóricos, el dinamismo del movimiento del sector estaría directamente relacionado con el dinamismo económico y la industrialización de los territorios, por un lado, y con su nivel de urbanización, por otro. Ambos factores (industrialización y concentración de población en las ciudades) están, en todo caso, estrechamente relacionados. La imagen que emerge de las entrevistas realizadas es que los TSAS más dinámicos y activos se observan en zonas urbanas de industrialización temprana. El desarrollo del TSAS, ligado al desarrollo de la sociedad civil organizada, sería, en cierta medida, y sin perjuicio de la concurrencia de otros factores, una función de los procesos de urbanización e industrialización de la modernidad.

\subsection{El papel histórico de los actores sociales}

En el discurso de los informantes entrevistados, la Iglesia Católica (en adelante Iglesia) y los propios afectados (reiteradamente nombrados con el significante "familias") son los protagonistas del relato histórico del sector social en España y en sus distintas regiones, con las particularidades que les son propias. Estos actores son los sujetos (activos y también pasivos) de los procesos que se desencadenan históricamente en el espacio de necesidades, oportunidades y restricciones abierto por los acontecimientos políticos y los factores económicos y territoriales que hemos esbozado hasta ahora. Como tales, estos actores preexisten al desarrollo del TSAS que tiene lugar entre los últimos años del franquismo y comienzos de la Transición política. Remiten a cauces o formas de solidaridad organizada históricamente previas a lo que, a partir de la década de 1980, se va a institucionalizar en la forma de TSAS. 
Hay, por supuesto, otros actores de incidencia, decisiva o complementaria, en la configuración histórica del TSAS en España. No puede obviarse en este sentido el papel desempeñado por las administraciones públicas. Éstas, con la apertura del periodo democrático y el desarrollo consiguiente de los dispositivos de gobierno de la política social a nivel del Estado y en las diferentes comunidades autónomas, han ido marcando progresivamente, como ya apuntamos, el estatus y el rol de las ETSAS, las reglas del juego que estas han tenido y tienen que jugar en la gestión de la cuestión social ${ }^{5}$. También hay que hacer referencia a entidades como cajas de ahorro y fundaciones dependientes de entidades financieras. Su importancia como cooperadores de las ETSAS ha sido notable, sobre todo en algunos territorios. Asimismo, el movimiento obrero y los profesionales de la intervención social, bien en solitario en concurrencia con movimientos vecinales o de afectados, han tenido un papel significativo en el surgimiento de entidades y en las dinámicas de transformación del sector.

No obstante, cuando se interroga a los informantes sobre el papel de los actores en la configuración del TSAS, el relato se centra en la significación histórica de las entidades vinculadas a la Iglesia Católica o a los propios afectados como agentes de incidencia decisiva. Por razones de espacio, pero también por el alcance que se les atribuye por los entrevistados, centraremos el análisis en estos actores considerados "protagonistas": la Iglesia y los afectados. En todo caso, más allá de papel de cada actor, la acción de la Iglesia y de las familias, junto al de movimientos vecinales y obreros, se entrelazan en la génesis del Tercer Sector de Acción Social, a veces por medio de vínculos de carácter personal, para ir separándose y autonomizándose a lo largo de las sucesivas etapas de su desarrollo.

\section{La matriz originaria}

En la etapa final de la Dictadura y en los comienzos de la Transición democrática se observa, a tenor de los relatos recogidos y en las fuentes consultadas, una amalgama en la que la confluyen dos tradiciones de movilización: una de raíz eclesial, y otra de raíz civil, en la que convergen a su vez iniciativas vecinales y de personas afectadas por determinadas carencias o necesidades, junto a movimientos de tradición obrera o, en algunas zonas, el cooperativismo.

Al describir esta amalgama originaria, en el discurso de los informantes entrevistados destacan dos actores:

- Por un lado, la Iglesia, como actor que ejerce un papel de liderazgo e impulso de iniciativas de solidaridad organizada sobre la base de su autoridad moral tradicional, políticamente legitimada durante la Dictadura, pero en el marco de una renovación de su rol social y político (Romeo et al, 2012).

- Por otro lado, las familias, como actores protagonistas en la formación de movimientos sociales orientados a resolver colectivamente los problemas vividos (hacer de las inquietudes privadas, problemas públicos, en la clásica formulación de Wright Mills).

5. La relación del TSAS con las administraciones públicas es objeto de estudio de otro de los artículos de este número monográfico. 
En este panorama, la discapacidad emerge como problemática y ámbito clave para la movilización de familias, pero también de organizaciones de raíz eclesiástica entreveradas con éstas. En torno a esta problemática de la discapacidad, se va a condensar la acción de familias, parroquias y organizaciones religiosas, operando como una suerte de espejo o de modelo para el desarrollo posterior del sector. Ciertamente, la discapacidad aparece de modo reiterado en los discursos recogidos como una especie de instancia pionera en la configuración del sector: "todo el Tercer Sector [nace] ligado sobre todo al ámbito de la discapacidad (...), es decir, familias que se unen para dar respuesta a una situación" (Entrevista 18, Expertos y grupos de interés, País Vasco). En este escenario hay que señalar específicamente el papel de las mujeres: "al principio eran mujeres sin cultura o familias sin cultura, pero sobre todo mujeres que reivindicaban que a sus hijos [con discapacidad] había que atenderles" (Entrevista 21, Internos al sector, País Vasco).

De este modo, Iglesia y afectados, en especial familias con hijos afectados por discapacidades, aparecen en la conciencia histórica de los informantes como referentes de movilización fundamentales, las instancias preliminares clave en la formación de lo que va a ser el TSAS:

Tenemos una rama que viene de instituciones religiosas (...); otra de padres y madres que articulan asociaciones porque tienen hijos con una diversidad funcional (Entrevista 42, Expertos y grupos de interés, Comunidad Valenciana).

La discapacidad, yo creo que fueron los primeros... Si yo miro para atrás creo que tuvieron un protagonismo muy importante.... Empezaron a salir con el tema de la discapacidad, con las asociaciones de familiares... El papel de las familias fue mastodóntico..., el papel de la Iglesia también fue importante.

(Entrevista 1, Expertos y grupos de interés, Andalucía)

\section{El papel de la Iglesia y sus transformaciones}

Casi sin excepción, los informantes entrevistados coinciden en reconocer que la Iglesia Católica ha ejercido una influencia decisiva en el origen y en el desarrollo del TSAS en España. Su acción, que viene de muy atrás, fue determinante en la generación de iniciativas diversas, que en sentido estricto desbordaban la cuestión social, a las que proporcionó liderazgo, impulso y soporte:

Buena parte de los movimientos sociales, movimientos políticos del Tercer Sector se fraguaron en la Iglesia, porque aquí la Iglesia dio un poco soporte. Muchas veces a través de otro tipo de iniciativas, iniciativas culturales, iniciativas deportivas, de iniciativas en educación (...) que fueron luego derivando en otro tipo de organizaciones.

(Entrevista 24, Internos al Sector, País Vasco)

La influencia la Iglesia ha sido, como es lógico, correlativa al peso que esta institución ha tenido históricamente en la vida política y en la sociedad españolas. De hecho, el apoyo de la Iglesia a movimientos e iniciativas sociales se da, como hemos apuntado ya, en el marco de una renovación de su rol social y político. Esta renovación va a estar en línea con los postulados del Concilio Vaticano Segundo y con la adopción de una actitud crítica por parte de ciertos 
sectores de la Iglesia respecto al tratamiento de las cuestiones sociales durante la Dictadura; un cambio de posicionamiento de su papel de sostén legitimador del régimen franquista, en definitiva, que será decisivo en su debilitamiento y en el proceso de Transición a la democracia (Juliá, 2017).

En la crisis final de la Dictadura y en los inicios del periodo democrático, la Iglesia Católica, sobre todo lo que se conoce comúnmente como "iglesia de base", se mantuvo abierta a las demandas de la sociedad. Esto se observa no solo en el impulso y apoyo directo a los movimientos sociales y sindicales ("No había asociación de vecinos que no tuviese local en la parroquia..." Entrevista 21, Internos al sector, País Vasco), sino también en la apertura a la participación de seglares en los órganos de gobierno de entidades de origen netamente eclesial.

Transcurrida la etapa de eclosión de ETSAS, la influencia de la Iglesia ha ido debilitándose por efecto del proceso de secularización y desinstitucionalización religiosa de las sociedades modernas, y, asimismo, por la propia dinámica de autonomización de entidades y movimientos sociales (que, aunque convergieran con la acción eclesiástica, también tenían, en muchos casos, su propia autonomía). De cualquier modo, las organizaciones sociales aprovecharon el soporte inicial de la Iglesia para dotarse de estructura y de capacidad de acción propias, derivando progresivamente en organizaciones autónomas ("hay instituciones sociales que [hoy] no son eclesiales, pero que tienen su origen en la Iglesia" Entrevista 3, Internos al sector, Andalucía).

También hubo transformaciones en las entidades de raíz eclesial, que tuvieron que llevar a cabo un proceso de reconversión o de "reinvención" motivado por factores internos (reemplazo generacional en las organizaciones, pérdida de vocaciones religiosas...) y externos (los propios cambios sociopolíticos derivados de la Transición, el proceso de secularización, la autonomización progresiva de las ETSAS...). En consecuencia, se van a ir configurando nuevas pautas de organización y de operación en las entidades eclesiásticas: incorporación de personal laico, profesionalización de la gestión, introducción de sistemas de calidad en la atención, etc. (Romeo et al, 2012: 30).

Para algunos informantes vinculados a entidades de carácter religioso, la Iglesia, en el desempeño de su función promotora, ha procurado en todo caso no significarse en exceso, de modo a dejar que el Tercer Sector se visibilizara como tal, y que finalmente las entidades se autonomizasen respecto al liderazgo eclesiástico que les sirvió inicialmente de impulso y matriz generativa. Esta ha sido "una actitud correcta para que el propio sector se estructure bien" (Entrevista 16, Internos al sector, País Vasco): ha permitido que las entidades hayan podido disponer de un espacio propio y de una interlocución directa con las Administraciones públicas. Cuando estos actores estuvieron en condiciones de hacerse cargo de sus propias necesidades "la Iglesia, gracias a Dios, se retira (...), entendió que hizo un servicio y que ya no le tocaba" (Entrevista 23, Internos al sector, País Vasco).

Como decimos estas pautas están muy generalizadas tanto en las regiones de mayor tradición industrial como en territorios más rurales o de cultura tradicional.

En Cataluña, gran parte del impuso al movimiento asociativo tiene su origen en la acción parroquial, si bien "la acción parroquial que había en cada pueblo ha dejado de ser importante" (Entrevista 28, Internos al sector, Cataluña). Con todo, todavía existen grandes organizaciones 
de raíz religiosa, cuya importancia es destacable en el sector (como Cáritas, indudablemente, o San Juan de Dios).

En el País Vasco, donde el peso del factor religioso-eclesiástico se reconoce como especialmente notable, la influencia de la Iglesia ha sido, correlativamente, decisiva. La Iglesia católica ha incidido originalmente en el abordaje de cuestiones educativas, lingüísticas e identitarias, entreveradas con las propiamente sociales, para ir luego replegándose de forma progresiva.

En Madrid, se reconoce la matriz comunitarista y cristiana de los movimientos sociales de la región, amalgamados con iniciativas de naturaleza secular. El liderazgo carismático de estos movimientos de raíz religiosa ha sido, además, base de reclutamiento y renovación de la clase política local en los ayuntamientos, así como en la dirección de las grandes entidades sociales.

En la Comunidad Valenciana, también el factor religioso ha tenido y "continúa teniendo un fuerte peso en la generación de tejido asociativo, de fundaciones (...) (que) se han ido reciclando y modernizando" (Entrevista 39, Externos y grupos de interés, Comunidad Valenciana). La acción social de la Iglesia está diversificada en múltiples organizaciones procedentes de órdenes religiosas o con base en las parroquias, así como en entidades que no son propiamente eclesiásticas, pero que surgen desde el cristianismo de base. No obstante, a juicio de los entrevistados, la influencia de la Iglesia en esta Comunidad habría sido menor que en otras, como el País Vasco o Cataluña.

En Castilla y León se identifica una menor incidencia de los procesos de secularización y la pervivencia de un modelo de caridad más tradicional por parte de la Iglesia y sus organizaciones. Este modelo de intervención se mantendría, sobre todo en ciertos ámbitos de actuación (exclusión y cooperación al desarrollo, menos en discapacidad).

En Andalucía, la influencia de la Iglesia se observa en el papel históricamente desempeñado por formas tradicionales y religiosas de asociación, como las hermandades y las cofradías. Este tipo de asociaciones, que ejemplifican la peculiaridad sociocultural andaluza, constituyen soportes para la solidaridad organizada en forma de ayuda mutua. En cualquier caso, más allá de estas formas asociativas tradicionales, la Iglesia ha desempeñado un importante papel de impulso a entidades, como Proyecto Hombre o Andalucía Acoge, orientadas hacia ámbitos de necesidad emergentes (drogodependencias, migraciones). Entidades que, como en otras regiones, han aprovechado el respaldo inicial de la Iglesia para convertirse después en organizaciones autónomas.

\section{Los movimientos de afectados y el rol de las familias}

El papel de la Iglesia no debe oscurecer la significación de los movimientos de afectados en la formación del sector. En los informantes pertenecientes a entidades laicas, se observa cierto esfuerzo discursivo por visibilizar su rol y justificar su autonomía respecto a la Iglesia. La importancia histórica de la Iglesia en el impulso al TSAS se reconoce indefectiblemente; pero, al mismo tiempo, se identifica una defensa de las entidades sociales laicas como una fuerza diferenciable, e incluso independiente, respecto al papel original de las organizaciones de filiación religiosa: 
La Iglesia estaba antes (...), pero, desde luego, la sociedad civil digamos se ha incorporado, con los esquemas que había, y lo ha hecho muy bien, también lo ha hecho muy bien; hay muchas organizaciones que funcionan muy, muy bien y no tienen que ver con la Iglesia, (...) hacen lo mismo que hacía, sin más, lo mismo que hacía la iglesia antes, quizá en otros ámbitos también que la Iglesia no cubría.

(Grupo Focal 14, Voluntariado, País Vasco)

La familia (o las "familias") constituye el significante clave que, en la memoria histórica de los informantes entrevistados, condensa el protagonismo de las iniciativas sociales en la constitución originaria del sector. Este reconocimiento del protagonismo de la familia es menor, no obstante, en regiones como Madrid y Cataluña, donde los significantes clave enunciados son otros ("asociaciones", "voluntarios", "movimientos vecinales"). Pero la familia aparece reiteradamente como referente fundamental en el resto, como si la unidad social básica originalmente constitutiva de asociaciones e iniciativas de vecinos estuviera formada, en efecto, por familias ${ }^{6}$.

Hay que decir que el impulso del asociacionismo familiar (como también del vecinal), se va a ver favorecido por dos cambios legislativos que acontecen en el tramo final de la Dictadura, la Orden Ministerial de 1963 y la Ley de Asociaciones de 1964, que van a posibilitar la creación de asociaciones vecinales y de cabezas de familia. En un primer momento serán sobre todo las asociaciones de cabezas de familia las que proliferen, dadas las mayores facilidades que presentaba su constitución y el desarrollo de sus funciones (Contreras-Becerra, 2013).

Al describir el rol de las familias en la formación del TSAS, los informantes identifican dos momentos diferenciables (podríamos decir que, por extensión, también serían predicables, en general, de movimientos asociativos y vecinales):

Un primer momento que se extendería desde finales de la década de 1960 hasta los comienzos del periodo democrático, caracterizado por el protagonismo directo y activo de las familias en la reivindicación de derechos y de soluciones a los problemas vividos. Estas movilizaciones van a ser especialmente notables en la organización de respuestas colectivas a las externalidades derivadas de los procesos de industrialización y concentración poblacional en contextos urbanos. El surgimiento de las primeras asociaciones de vecinos, la movilización de las familias en el ámbito de la discapacidad o el movimiento de asociaciones de mujeres, "que surgen pegadas a los barrios cuando en la época industrial se asienta población inmigrante" (Entrevista 16, Internos al sector, País Vasco), se inscriben, ciertamente, en estas dinámicas.

Estas primeras movilizaciones introducen elementos de transformación decisivos para el desarrollo del sector: incorporan modos de acción social distintos a las formas tradicionales de acción tutelada o al mutualismo informal. Se constituyen de este modo asociaciones de autoayuda de base local, en las que la comunidad y las familias, "sobre todo padres de niños con

6. En este sentido, las categorías de "familias", "asociaciones", "movimientos vecinales", etc., mediante las que se articula la representación realizada por nuestros informantes, no deben considerarse como mutuamente excluyentes. Creemos que lo que se predica de las "familias" también sería atribuible, en general, a las otras categorías. En todo caso, nos ceñimos aquí al marco cognitivo y semántico enunciado por los informantes entrevistados. 
alguna carencia" (Entrevista 2, Internos al sector Andalucía), asumen un protagonismo activo en la reivindicación de sus derechos, así como en la satisfacción de sus necesidades.

El segundo momento se daría a partir de la década de 1980. En las entrevistas, se señala un corte histórico, un corte generacional incluso, en el papel de las familias como núcleo promotor de iniciativas sociales y de asociaciones. El desarrollo de los servicios sociales y el nuevo papel asignado a las ETSAS en su relación con las administraciones públicas traen consigo una progresiva a orientación a la provisión de servicios, caracterizada por la profesionalización y por la dependencia respecto a aquellas:

El movimiento de familias pasa de una época reivindicativa, centrada en los derechos (...), casi sin profesionales, a tener profesionales, ser más pasivos, entender que son más usuarios de servicios que socios activos en la entidad. (...) [N]o tiene nada que ver el movimiento de la época de la Transición con el movimiento de las familias ahora.

(E16, Internos al sector, País Vasco)

Este esquema narrativo puede considerarse generalizado en la muestra regional analizada, especialmente en los núcleos urbanos e industriales que, como vimos, concentran las iniciativas sociales más consistentes y activas de España. Todo ello, por supuesto, con énfasis y particularidades territoriales:

En Cataluña, los tempranos procesos de desarrollo industrial han constituido el caldo de cultivo de movimientos vecinales y obreros orientados a satisfacer las necesidades derivadas de la concentración urbana y la industrialización. El papel de la familia se desdibuja en el discurso de los informantes catalanes frente al protagonismo de un rico tejido asociativo y a una cultura del voluntariado que aún persiste. Según los informantes entrevistados, esta cultura del voluntariado dota de una impronta distintiva no solo al TSAS catalán, sino que involucra a "asociaciones desde culturales hasta pasando por todo lo que es ocio y tiempo libre de chicos, chicas, preservación del medioambiente..." (Entrevista 29, Externos y grupos de interés, Cataluña). En todo caso, el arraigo del asociacionismo y del voluntariado en Cataluña tendrían varias fuentes históricas distinguibles y finalmente convergentes:

- Los movimientos vecinales, muy relacionados con las migraciones interiores a las ciudades catalanas ("donde llegó más inmigración, ha habido siempre estas entidades asociativas", Entrevista 29, Externos y grupos de interés, Cataluña). Movimientos orientados a la ayuda mutua y a la cohesión comunitaria, cuya vigencia se ha podido percibir en las asociaciones surgidas durante la crisis de 2008.

- En una línea similar, los movimientos obreros, de los que "nacieron las primeras obras de ayuda mutua, mutualidades" (Entrevista26, Externos y grupos de interés Cataluña).

- La tradición de los clubes juveniles de tiempo libre, como los esplais o los boy scouts, de gran arraigo en Cataluña: "El movimiento scout cuando llegó de Inglaterra llegó a Barcelona; la primera asociación constituida en toda España es en Barcelona" (Entrevista 30, Internos al sector, Cataluña).

- Aunque desborde el ámbito de la acción social, hay que hacer referencia al papel histórico de la burguesía y la tradición asociativa y cultural catalanista, "con anhelos culturales, con anhelos económicos, que crea sus propias entidades, como ateneos, clubes 
de lectura" (Entrevista 26, Externos y grupos de interés, Cataluña). Un papel que hay que poner en relación con el desarrollo del movimiento de orientación identitaria que, a fines del siglo XIX, tendrá como propósito de hacer de Cataluña un ámbito cultural autónomo (Cacho Viu, 1997; Juliá, 2004).

En el caso del País Vasco, más allá de los rasgos derivados de los procesos de industrialización y concentración urbana, sobre todo en la zona del Gran Bilbao, los informantes ponen el énfasis expresamente en el papel de las familias, en el movimiento cooperativo y en el de las ikastolas, que se dan originalmente de forma entrelazada. La capacidad movilizadora de las familias entronca, en efecto, a tenor de los discursos recogidos, con la corriente que, desde finales de la década de 1960, promueve el cooperativismo en la actividad económica y el movimiento de las ikastolas en el ámbito educativo. El elemento común tanto al cooperativismo, al movimiento de las ikastolas y a los movimientos sociales en el ámbito de la discapacidad es similar: familias que se unen y se comprometen para dar respuesta a una necesidad:

Yo creo que finales de los años 60 fue un momento con mucha iniciativa social en el País Vasco. Yo destacaría esos tres elementos: el movimiento cooperativo, por un lado; el movimiento de ikastolas, que también nace desde una base similar; y luego todo el Tercer Sector ligado sobre todo al ámbito de la discapacidad, que también nace desde una perspectiva similar, es decir, familias que se unen para dar respuesta a una situación.

(Entrevista 18, Externos y grupos de interés, País Vasco)

El movimiento obrero, ligado al cooperativismo, tuvo asimismo una especial incidencia en Vizcaya en especial la Margen izquierda del Nervión, dando origen a proyectos solidarios y cooperativos (enseñanza, consumo, recursos sociales de autoayuda...), convergentes con iniciativas del Tercer sector.

En Madrid destaca también el dinamismo de iniciativas vecinales y asociativas, que han hecho de esta región un espacio de innovación con efectos históricamente sostenidos de movilización y generación de capital social. Desde la segunda mitad de la década de 1960, ha tenido lugar en Madrid una eclosión permanente de movimientos sociales que han dado lugar a asociaciones, fundaciones y cooperativas que, a la vez que reclamaban derechos, daban respuesta a necesidades no cubiertas por el sector público. Cabe señalar que, hacia el final de la Dictadura, en Madrid se desarrollaron las asociaciones vecinales más activas de España de las que, como se evoca en las entrevistas, han surgido iniciativas sociales de signo muy diverso a lo largo de las últimas décadas (lucha por la integración de personas con discapacidad, contra la droga, por la igualdad de género, formas de una economía solidaria, etc.). Estas iniciativas vecinales han sido fuente de origen de asociaciones progresivamente especializadas, y también para el reclutamiento de líderes asociativos.

En la Comunidad Valenciana, los informantes refieren, ya lo vimos, un TSAS muy heterogéneo en sus fuentes de origen, modalidades organizativas y objetivos. Junto a la influencia general de la Iglesia, destacan el papel tradicional de la familia ("el rol de la familia también ha sido importante, (...) vinculado a ese imaginario social, a ese elemento cultural del papel familiar" Entrevista 39, Externos y grupos de interés, Comunidad Valenciana) y, significativamente el de iniciativas familiares que van a operar en el ámbito de la discapacidad ("padres y madres 
que articulan asociaciones porque tienen hijos con una diversidad funcional", Entrevista 42, Externos y grupos de interés, Comunidad Valenciana). Otras bases de formación del sector proceden de movimientos sociales de distinto signo o de la respuesta social a las situaciones de pobreza y exclusión derivadas de la extensión de la zona de vulnerabilidad acontecida en las últimas décadas (movilizaciones que han tenido una "incidencia política en estos últimos años importante", Entrevista 42, Externos y grupos de interés, Comunidad Valenciana).

En Andalucía, se reproduce el esquema básico de movilización que se observa en otras regiones. Como ya señalamos, los movimientos vecinales y las familias, junto a la Iglesia, de manera diferenciada o en colaboración, constituyen la triple fuente originaria del TSAS andaluz. Los informantes coinciden en que el primer ámbito de expansión es el de la discapacidad en el que principalmente las familias lideraron la creación de una red de entidades, generalmente de apoyo mutuo, dedicadas a la atención a las problemáticas de sus propios miembros. Sobre esta expansión primera de entidades centradas en la discapacidad va a incidir el desarrollo de dispositivos públicos de política social, que van a apoyar y canalizar las demandas de las familias (Casado, 2003). Este proceso dará lugar a un cambio de rol en el movimiento asociativo de base local o vecinal, que va a trascender su originario papel reivindicativo o de demandante de recursos para convertirse también en gestor de servicios sociales de proximidad.

En Castilla y León destaca la base original constituida por las formas tradicionales de cooperación y ayuda mutua ligadas a la familia y al ámbito rural. Estas pautas tradicionales han coexistido con el desarrollo en las últimas décadas de asociaciones e iniciativas sociales más modernas y profesionalizadas, especialmente en los núcleos urbanos de la región. Los procesos de éxodo poblacional y envejecimiento que afectan al mundo rural, así como el desarrollo de los dispositivos de gobierno autonómicos, han debilitado las bases tradicionales de encauzamiento de la solidaridad organizada. Así, en los discursos recogidos se señala que las especificidades propias del carácter rural-tradicional de la región tienden a disolverse en las dinámicas de modernización del sector. No obstante, en el medio rural castellanoleonés se mantiene cierto nivel de acción de tipo cultural, o de movimientos vinculados "a la tierra", y asimismo pervive un modelo de intervención asistencial de raíz eclesiástica.

\section{Conclusiones}

Los efectos derivados de los procesos desencadenados por el fin de la Dictadura y la Transición a la democracia delimitan, en su conjunto, las condiciones que permiten el pleno desarrollo del TSAS en España: por un lado, el reconocimiento de un catálogo de derechos fundamentales y libertades públicas en cuya virtud el asociacionismo y la movilización social podrán desarrollarse sin las restricciones del periodo anterior; por otro lado, durante la Transición se establecen las bases políticas y jurídicas de la construcción de un Estado del bienestar moderno y descentralizado, con los dispositivos de gobierno que le son propios. Tales cambios establecen, a nuestro modo de ver, el marco de las condiciones políticas de posibilidad del TSAS: garantía de los derechos de asociación; reconocimiento de necesidades sociales que, 
progresivamente, van a ir institucionalizándose como derechos; constitución al efecto de las estructuras de gestión de las políticas sociales autonómicas... La construcción del Estado de bienestar español, apoyado en los dispositivos de gobierno autonómicos correspondientes, va a sentar las bases para el establecimiento de relaciones de colaboración entre el sector público y el mundo asociativo, en el marco de un sistema mixto de gestión de los asuntos considerados como sociales. La acomodación de las ETSAS en su espacio funcional dará paso a un proceso de racionalización y profesionalización de estas entidades, que con el tiempo irán perdiendo parte de su vigor crítico. Proceso que irá en paralelo a la asunción de un rol prevalente como organizaciones proveedoras de servicios, marcado por la dependencia con respecto a los fines y modos de financiación establecidos por las Administraciones públicas.

La construcción del Estado de bienestar español, apoyado en los dispositivos de gobierno autonómicos correspondientes, va a sentar las bases para el establecimiento de relaciones de colaboración entre el sector público y el mundo asociativo, en el marco de un sistema mixto de gestión de los asuntos considerados como sociales. La acomodación de las ETSAS en su espacio funcional dará paso a un proceso de racionalización y profesionalización de estas entidades, que con el tiempo irán perdiendo parte de su vigor crítico. Proceso que irá en paralelo a la asunción de un rol prevalente como organizaciones proveedoras de servicios, marcado por la dependencia con respecto a los fines y modos de financiación establecidos por las Administraciones públicas.

La posibilidad de identificar, en línea con la hipótesis rectora del Proyecto PECOTSAS, modelos distinguibles de TSAS según un patrón de diferenciación autonómico no se fundamenta solo en la configuración política y administrativa territorialmente diferencial inherente al Estado de las autonomías. Creemos que las diferencias en los patrones de desarrollo económico, distribución poblacional y tradiciones históricas de movilización presentes en las distintas regiones de España, así como en el interior de estas, poseen una mayor capacidad de inducir, correlativamente, diferencias regionales e intrarregionales en el sector. De este modo, sobre la base de una estructura de posibilidades políticas formalmente similar, el sector presenta un alto grado de heterogeneidad, tanto a nivel interregional como intrarregional. Las diferencias en las configuraciones regionales del TSAS, con independencia de si tales diferencias constituyen modelos o si, más simplemente, representan estilos de relación con las administraciones 0 graduaciones en el dinamismo de las entidades, tendrían, por tanto, una raíz histórica.

Las regiones con TSAS más dinámicas, y que en la representación de los informantes entrevistados constituyen frecuentemente el modelo de referencia (incluso su referente aspiracional), coinciden con regiones de industrialización temprana y elevada concentración poblacional y actividad económica en áreas urbanas. Las mismas regiones (Cataluña, País Vasco, Madrid) en las que las movilizaciones sociales (iniciativas vecinales, asociaciones de base familiar) del final de la Dictadura y la Transición fueron más activas.

A pesar de ello, en estas regiones de industrialización temprana encontramos diferencias internas. La distinción entre el medio rural y el urbano induce igualmente efectos ad intra en estas zonas. Y en Madrid, Cataluña o el País Vasco se identifican configuraciones de TSAS diferenciales en función de esta pertenencia rural/urbana. 
En regiones, como Andalucía, de industrialización tardía, y en todo caso limitada, en barrios de ciudades en las que ha habido cierta concentración de actividad industrial se identifican dinámicas comparables a las de las Madrid, Barcelona o el Gran Bilbao. En las áreas rurales de Andalucía, con carácter general, la concentración y articulación de las ETSAS ha sido menor. Las formas adoptadas por las entidades del medio rural y sus pautas de actuación responden a otras claves, más tradicionales (localismo, comunitarismo, ayuda mutua). También en Valencia y en Castilla y León opera internamente, de forma muy marcada, la distinción entre lo rural y lo urbano a efectos de presencia y actividad de las ETSAS. En estas regiones de industrialización tardía son las ciudades las que concentran el tejido del sector.

En estos focos urbanos e industriales, de tradición más reivindicativa y originalmente más activos, los movimientos sociales han conservado buena parte de su vigor. Los procesos de movilización observados durante la crisis de 2008, y actualmente, en el contexto de la Covid-19, muestran ciertamente la consistencia de la iniciativa social en ciudades como Madrid y Barcelona.

De este modo, el TSAS se concibe como un fenómeno originaria y fundamentalmente urbano, ligado históricamente a las carencias y necesidades provocadas por los procesos de concentración desordenada de actividad industrial y población en las ciudades. En las zonas rurales, en todas las regiones estudiadas, el TSAS tiende a ser valorado como un fenómeno marginal y muy vinculado a formas tradicionales de organizar la solidaridad y la ayuda mutua (con excepción de ciertas áreas de Guipúzcoa, que presentan particularidades derivadas de su patrón de desarrollo industrial endógeno).

Las familias y las organizaciones eclesiásticas, cuyas acciones se entrelazan inicialmente, aparecen como los principales vertebradores de la acción de movimientos vecinales, de grupos de afectados e iniciativas de signo diverso en los periodos de formación e institucionalización del TSAS. En esta especie de matriz preformativa, que emerge reiteradamente en los discursos recogidos, la problemática de la discapacidad aparece, a su vez, como ámbito pionero. En todo caso, la prevalencia de la acción familiar y eclesiástica en la formación del TSAS invita a atribuir una hipotética impronta conservadora a la génesis del sector en España, con independencia del talante crítico de tales movimientos o de sus posibles adscripciones político-ideológicas. Una matriz común al conjunto de España (aunque con una intensidad más acusada en algunos territorios de la muestra analizada, como Castilla y León, Andalucía o el País Vasco). Así lo sintetiza uno de los expertos entrevistados:

Cuando yo digo que la religión y la familia han sido los elementos que en parte explican el desarrollo del Tercer Sector, parto desde esa lógica también de sociedad conservadora (...) que explica las relaciones sociales que se han ido articulando en base a esos elementos, $y$ que yo creo que han estado presentes, y que en parte hoy en día, a pesar de toda la transformación que se ha producido (...), siguen estando presentes (...); quiero decir, en España la familia tiene un peso específico concreto en todos los lugares.

(Entrevista 18, Externos y grupos de interés, País Vasco)

La configuración autonómica del Estado de bienestar en España, en la forma de un modelo mixto de gestión, introduce, como decíamos, la posibilidad de un desarrollo correlativamente 
diferencial de los TSAS regionales. Sin embargo, esta sería más bien una posibilidad teórica. A título de hipótesis, creemos que, a pesar de la diferenciación en las formas de relación entre ETSAS y administraciones públicas que se puedan observarse en cada ámbito autonómico, las pautas básicas tienden a ser convergentes. A nuestro modo de ver, sobre la base de los discursos recogidos, las diferencias más significativas radican en los patrones económicos y demográficos territoriales, y en la historia que los condiciona.

Financiación: Estudio realizado en el marco del Proyecto "PECOTSAS: Perspectiva Comparada del Tercer Sector de Acción Social" financiado en la Convocatoria 2017 de Proyectos de I+D+i de excelencia del Ministerio de Economía, Industria y Competitividad (RFA: CSO201785486-P).

\section{Bibliografía}

ALBERICH, T. (2007): "Asociaciones y Movimientos Sociales en España: Cuatro décadas de Cambios", Revista de Estudios de Juventud, 76, 71-89.

ALONSO, L.E. (1995): "Sujeto y discurso: El lugar de la entrevista abierta en las prácticas de la sociología cualitativa". En: Delgado, J.M. \& Gutiérrez, J. (Coords.), Métodos y técnicas cualitativas de investigación en ciencias sociales, Síntesis.

CACHO VIU, V. (1997): Repensar el noventa y ocho, Biblioteca Nueva.

CASADO, D. (2008): "Régimen Institucional en España del Sector Voluntario y opciones de perfeccionamiento", Revista Española del Tercer Sector, 10, 69-106.

CONTRERAS-BECERRA, J. (2013): "El movimiento vecinal en Andalucía durante el tardofranquismo y el proceso de cambio político (1968-1986): ¿excepcionalidad o actor destacado?”, Gerónimo de Ustáriz, 28-29, 95-122.

FLORES, M. (2012): Lucha Santa. Experiencia religiosa de los curas obreros en la Sierra Sur de Sevilla, PPC.

GIL PECHARROMÁN, J. (2019): La estirpe del camaleón. Una historia política de la derecha en España (1937-2004), Penguin Random House.

GONZÁLEZ PORTILLO, A. \& JARAÍZ, G. (2019): “Voluntariado y Tercer Sector en Andalucía: Revisando el pasado, mirando el futuro”. En: Márquez Zárate, M.A., Ramírez Pérez, M.A. \& Martínez García, M.R. (Coords.), La incidencia de las organizaciones de la sociedad civil en las políticas públicas de ámbito local, Universidad Pablo de Olavide-UNAM.

JULIÁ, S. (2004): Historias de las dos Españas, Santillana. 
JULIÁ, S. (2017): Transición. Historia de una política española, Galaxia Gutenberg.

MARBÁN, V. (2014): "Tercer Sector de Acción Social y lucha contra la exclusión”, VII Informe sobre exclusión y desarrollo social en España 2014, Documento de trabajo 5/11. FOESSA-Caritas Española.

MARBÁN, V. \& RODRÍGUEZ, G. (2006): “Estado de bienestar y tercer sector social en España. El estado de la investigación social", CIRIEC-España, Revista de Economía Pública, Social y Cooperativa, 56, 117-139.

MORA, S. (2020): Voces insólitas. La participación de las personas en proceso de exclusión en el tercer sector de acción social como espacio político, Tesis doctoral (inédita), Universidad de Zaragoza.

PLATAFORMA DE ONG DE ACCIÓN SOCIAL, POAS (2012): II Plan Estratégico del Tercer Sector de Acción Social (2013-2016), POAS.

RADCLIFF, P. (2009): "Las asociaciones y los orígenes de la transición en el segundo franquismo". En: Townson, N. (Ed.): España en cambio. El segundo franquismo, 1959-1975, Madrid: Siglo XXI, 129-156.

RODRÍGUEZ CABRERO, G. (2014): "Estado de bienestar en España: transformaciones y tendencias de cambio en el marco de la Unión Europea". En: F. Lorenzo Gilzanz (Ed.), VII Informe sobre exclusión y desarrollo social en España, FOESSA-Cáritas, 229-394.

RODRÍGUEZ CABRERO, G. (2020): "El Tercer Sector de Acción Social en España. Desarrollo reciente y retos de futuro", Anales de Derecho y Discapacidad, 5, 221-240.

RODRÍGUEZ-CABRERO, G. \& MARBÁN, V. (2015): Análisis prospectivo sobre los retos actuales y futuros del Tercer Sector de Acción Social. Parte I: El Tercer Sector de Acción Social en el contexto de la Unión Europea. Situación actual y tendencias de futuro del TSAS en España, POAS.

RODRÍGUEZ CABRERO, G. \& SOSVILLA, S. (2018): Las fundaciones de acción social en España frente a la crisis. Impacto social y económico, Asociación Española de Fundaciones.

ROMEO, Z., LÓPEZ-ARÓSTEGUI, R., CASTILLO, R. \& FERNÁNDEZ, I. (2012): Historia del Tercer Sector de Acción Social de Bizkaia. Construyendo alternativas solidarias desde el territorio, $\mathrm{Ob}$ servatorio del Tercer Sector de Bizkaia.

TOWNSON, N. (ED.) (2009): España en cambio. El segundo franquismo, 1959-1975, Siglo XXI, 129-156.

VÁZQUEZ BARQUERO, A. (1988): Desarrollo local. Una estrategia de creación de empleo, Pirámide. 
